Erratum

\title{
Erratum to "Comparative Pharmacokinetics of Levofloxacin in Healthy and Renal Damaged Muscovy Ducks following Intravenous and Oral Administration"
}

\author{
Mohamed Aboubakr ${ }^{1}$ and Ahmed Soliman ${ }^{2}$ \\ ${ }^{1}$ Department of Pharmacology, Faculty of Veterinary Medicine, Benha University, Moshtohor, Toukh, Qaliobiya 13736, Egypt \\ ${ }^{2}$ Department of Pharmacology, Faculty of Veterinary Medicine, Cairo University, Giza 12211, Egypt
}

Correspondence should be addressed to Mohamed Aboubakr; mohamedhafez19@yahoo.com

Received 23 February 2014; Accepted 2 March 2014; Published 16 March 2014

Copyright (C) 2014 M. Aboubakr and A. Soliman. This is an open access article distributed under the Creative Commons Attribution License, which permits unrestricted use, distribution, and reproduction in any medium, provided the original work is properly cited.

The following errors occurred in Table 2 and Page 4.

AUMC value in healthy ducks is $73.46 \mu \mathrm{g} \mathrm{mL}^{-1} \mathrm{~h}^{-2}$ instead of $37.46 \mu \mathrm{g} \mathrm{mL}^{-1} \mathrm{~h}^{-2}$.

MAT value in healthy ducks is $0.74 \mathrm{~h}$ instead of $0.31 \mathrm{~h}$ and MAT value in renal damaged ducks is $0.70 \mathrm{~h}$ instead of $2.08 \mathrm{~h}$, with no significance in MAT between healthy and renal damaged ducks.

In Page 4, last line in left column, low MAT (mean absorption time) value is $0.74 \mathrm{~h}$ instead of $0.31 \mathrm{~h}$. 
TABLE 2: Pharmacokinetic parameters of levofloxacin in healthy and renal damaged ducks after a single PO administration of $10 \mathrm{mg} \mathrm{kg}^{-1} \mathrm{bwt}$ $(n=6)$.

\begin{tabular}{lccc}
\hline Parameter & Unit & Healthy & Renal damaged \\
\hline$K_{\mathrm{ab}}$ & $\mathrm{h}^{-1}$ & $3.31 \pm 0.10$ & $0.47 \pm 0.07^{* * *}$ \\
$K_{\mathrm{el}}$ & $\mathrm{h}^{-1}$ & $0.24 \pm 0.02$ & $0.18 \pm 0.01^{*}$ \\
$t_{1 / 2(\mathrm{ab})}$ & $\mathrm{h}$ & $0.22 \pm 0.01$ & $1.45 \pm 0.08^{* * *}$ \\
$t_{1 / 2(\mathrm{el})}$ & $\mathrm{h}$ & $2.89 \pm 0.09$ & $3.94 \pm 0.14^{* * *}$ \\
$C_{\max }$ & $\mu \mathrm{g} \mathrm{mL}^{-1}$ & $3.63 \pm 0.12$ & $4.05 \pm 0.13$ \\
$t_{\max }$ & $\mathrm{h}$ & $2.05 \pm 0.08$ & $2.47 \pm 0.11^{*}$ \\
AUC & $\mu \mathrm{g} \mathrm{mL}^{-1} \mathrm{~h}^{-1}$ & $17.97 \pm 2.24$ & $37.38 \pm 2.28^{* * *}$ \\
AUMC & $\mu \mathrm{g} \mathrm{mL}^{-1} \mathrm{~h}^{-2}$ & $73.46 \pm 2.61$ & $255.49 \pm 17.59^{* * *}$ \\
MRT & $\mathrm{h}$ & $4.08 \pm 0.14$ & $6.83 \pm 0.19^{* * *}$ \\
MAT & $\mathrm{h}$ & $0.74 \pm 0.08$ & $0.70 \pm 0.07$ \\
$F$ & $\%$ & $73.56 \pm 2.38$ & $71.88 \pm 2.42$ \\
$C_{\text {max }} / \mathrm{MIC}$ & $\mathrm{Ratio}$ & $36.29 \pm 2.44$ & $40.52 \pm 2.47$ \\
AUC/MIC & Ratio & $179.72 \pm 11.35$ & $373.81 \pm 21.03^{* * *}$ \\
\hline
\end{tabular}

${ }^{*} P<0.05,{ }^{* * *} P<0.001$ refers to degree of significance.

$k_{\mathrm{ab}}$ : first-order absorption rate constant; $K_{\mathrm{el}}$ : elimination rate constant; $t_{1 / 2(\mathrm{ab})}$ : absorption half-life; $t_{1 / 2(\mathrm{el})}$ : elimination half-life; $C_{\max }:$ maximum plasma concentration; $t_{\max }$ : time to peak plasma concentration; MAT: mean absorption time; $F$ : fraction of drug absorbed systemically after PO administration; $C_{\max } / \mathrm{MIC}$ : maximum serum concentration/minimum inhibitory concentration ratio; AUC/MIC: area under concentration-time curve/MIC ratio. 

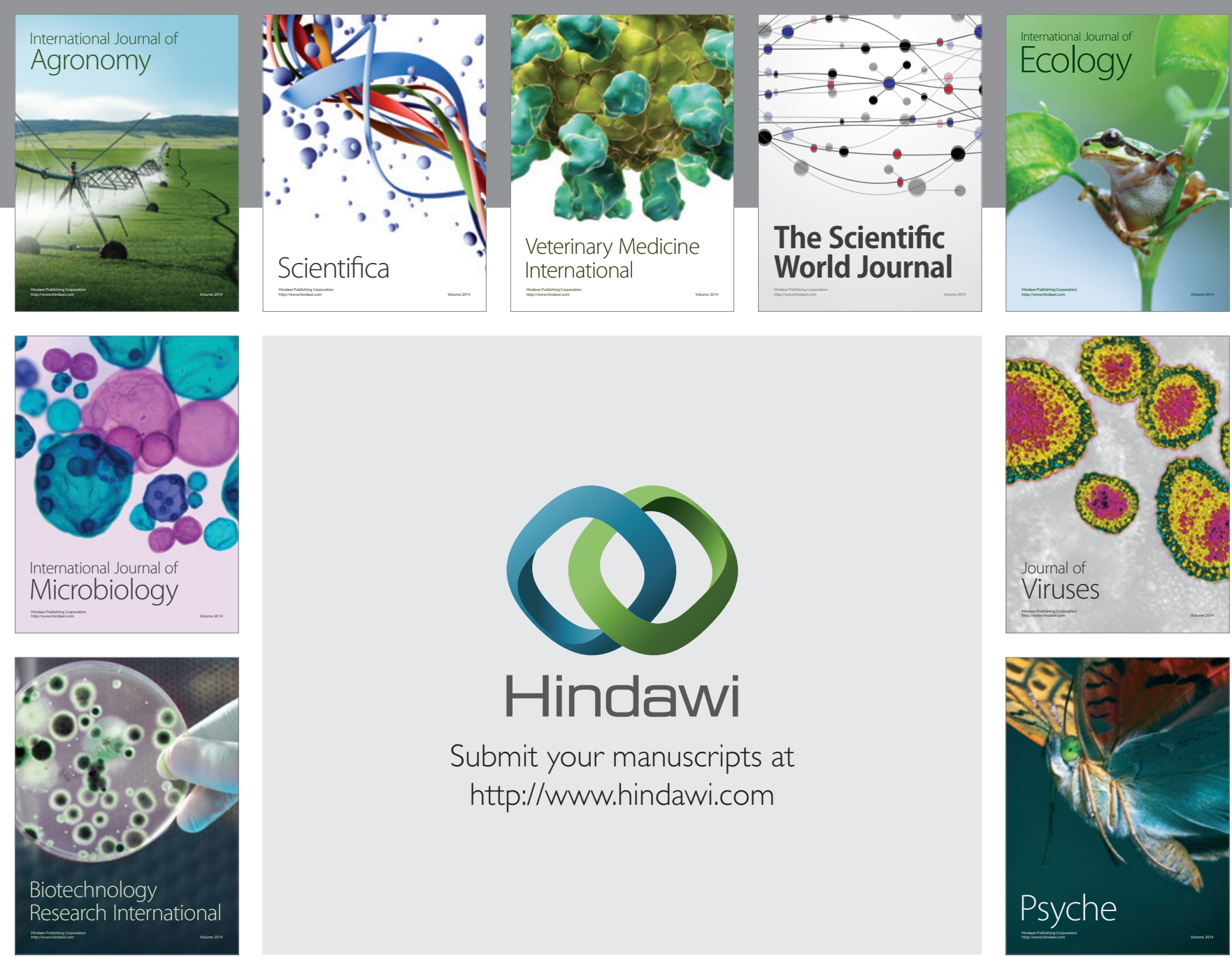

Submit your manuscripts at http://www.hindawi.com
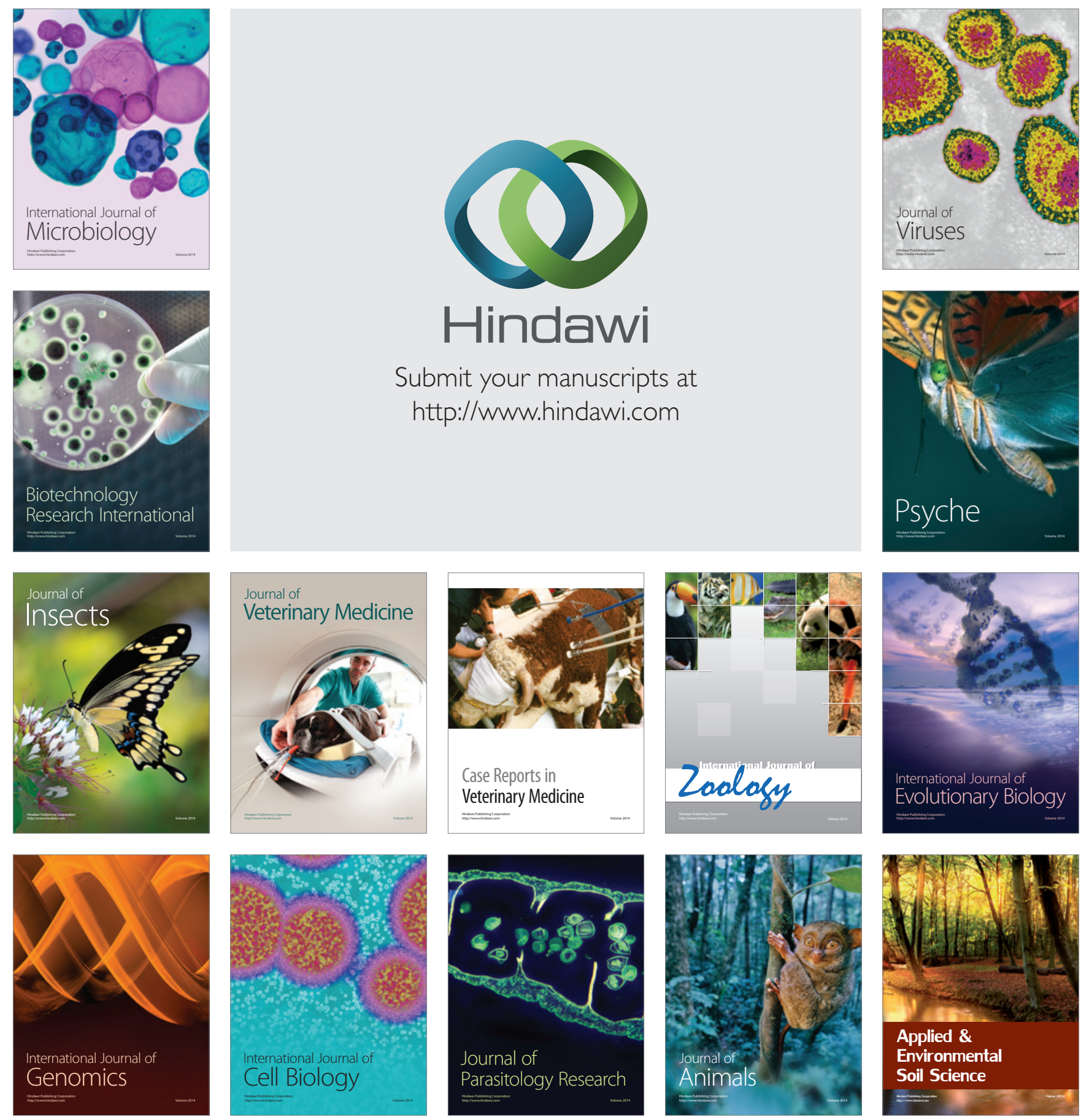